\title{
A Novel Model To Predict Endometriosis in Patients with Ovarian Cysts: A Retrospective Study.
}

\author{
Junmiao Xiang \\ Wenzhou Medical University \\ Wei Shen \\ Le Jiu Medical \\ Zongwen Liang \\ Wenzhou Medical University \\ Qiong Zhang \\ Wenzhou Medical University \\ Ping Duan ( $\square$ wzfkN11@163.com ) \\ Wenzhou Medical University
}

\section{Research}

Keywords: Endometriosis, ovarian cyst, CA-125, CA-19-9, logistic regression modeling

Posted Date: August 12th, 2021

DOI: https://doi.org/10.21203/rs.3.rs-762131/v1

License: (c) (i) This work is licensed under a Creative Commons Attribution 4.0 International License. Read Full License 


\section{Abstract}

\section{Objective}

To develop a model that uses hematological indexes and clinical characteristics to help estimate the probability of endometriosis in patients with ovarian cysts.

\section{Methods}

A retrospective study was conducted on 2242 patients who underwent surgery for benign ovarian cysts from January 2008 to November 2016. Variables included in the model were serum tumor markers, blood routine test, age, BMI, reproductive history, history of hysteroscopy, menstrual episodes. Logistic regression was used to construct a predictive model for endometriosis, Receiver Operating Characteristic curves and the areas under the curve was used to verify the model's validities. Ten-fold cross-validation was primarily used as an internal validation to evaluate the prediction accuracies of the model. Normalized mean square errors (NMSE) was obtained to compare the reliability of different models.

\section{Results}

978 (43.6\%) patients with endometriosis were included in the strudy. Univariate analysis showed that age, BMI, delivery, dysmenorrhea, menstrual cycle, duration of menstrual flow, history of hysteroscopy, CA-125 and CA-19-9 $(P<0.001)$ are associated with endometriosis. The area under the receiver operating characteristic curve for the model with CA-125 alone was 0.888 , with a sensitivity of $81.6 \%$ and specificity of $83.5 \%$. After adjustment for other multiple covariates, including age, mature delivery, irregular menstruation, dysmenorrhea, menstrual period, history of hysteroscopy, CEA, CA-19-9, monocyte count, platelet count, the model obtained had an AUC of 0.916 , with a sensitivity of 0.849 and specificity of 0.864 .

\section{Conclusions}

The diagnostic prediction model can be used as a framework for potential improvement in diagnosis of endometriosis in patient with ovarian cyst.

\section{Introduction}

Endometriosis is one of the most common benign gynecological disorders occurring in 6 to $10 \%$ of the general female population[1]. It is defined as the development of endometrial tissue (gland and stroma) outside the uterus such as, ovaries, pelvic peritoneum, and rectovaginal space. Endometriosis is a recurring persistent disease that causes non-menstrual pelvic pain, dyspareunia infertility, dysmenorrhea, and menstrual irregularities [2]. It is reported as a disease of complex multifactorial etiology, among all the hypothesis, transplantation of endometrial tissues via retrograde menstruation is widely accepted [3]. The correlation between symptoms and lesions is quite incomprehensible because the symptoms are nonspecific and not diagnostic.[4]. 
The diagnosis of endometriosis is based on clinical manifestations and imaging techniques [5] but confirm diagnosis of the disease can only be obtain by invasive procedures like direct visualization of peritoneal and ovarian implants by laparoscopy or laparotomy followed by histological analysis [6]. To increase the accuracy of the diagnosis of endometriosis, especially to avoid the use of invasive management, some investigators have begun to characterize the factors contributing to the detection of endometriosis. There is evidence that family history, immunological, menstrual and reproductive factors and are associated with endometriosis[7], different combinations of these biomarkers, are studied to increase the diagnostic accuracy of this disease.[8-10] The development of multiple factors to improve the accuracy of diagnosis of endometriosis is necessary.

The novel model was synthesized by correlating patient's hematological indexes and clinical characteristics in a multivariate regression model which could help us to recognize which ovarian cysts are more likely to be biopsied so as endometriosis can be diagnosed in early stage.

\section{Materials And Methods}

\section{Patients}

Retrospective data were collected from The Second Affiliated Hospital of Wenzhou Medical University. A total of 2242 premenopausal women who underwent either laparoscopic or laparotomic surgery in the Gynecology Department of our hospital from January 2008 to November 2016 were included in this study. Patients who underwent surgery for ovarian endometriosis, which was confirmed by surgical specimen histopathological examinations were eligible for our study. The exclusion criteria as follows: history of hormonal therapy for endometriosis, pregnant woman, abnormal hepatic and renal function tests, pelvic inflammatory disease, pathologically confirmed or clinically diagnosed with leiomyoma or adenomyosis, acute infection or history of chronic inflammatory disease, immune system diseases, or malignancy.

\section{Data Collection}

The data were obtained by reviewing the patients' medical records. All patients underwent routine preoperative laboratory studies, including CA-125, CA-19-9, carcinoembryonic antigen (CEA) and a complete blood count test was performed prior to surgery. Patient-related factors assessed included endometriosis-related symptoms, age, body mass index (BMI), reproductive history (mature delivery, premature delivery, abortion), menstrual history (menstrual cycle, duration of menstrual flow), surgical features (history of laparotomy, laparoscopy or hysteroscopy) and histopathology diagnosis following surgery were retrieved for each patient.

Most patients in the study had preoperative ultrasonographic evaluations. The reasons why we do not bring in the ultrasonographic diagnosis of cysts in the study were that sonographic evaluations were performed by different sonographers, transducers and types of ultrasounds. 


\section{Statistical Analysis}

Patients characteristics were compared by using variance analysis (t-test, for continuous variables), chisquare test (for dichotomous variables) or Kruskal-Wallis test (for continuous variables in skewed distribution) [11]. Logistic regression was used to perform multivariate analysis, and forward method was used to select variables[12]. 10-fold cross validation was used to predict the accuracy of the internal validation model. We randomly divided the data set into 10 copies, with 9 of them as a training set, used to establish the forecast model, the remaining 1 data set as a validation set, as a validation set. Training set to build the model, with the validation set to predict, this process was continued for 10 times and ultimately obtained a complete set of predictions. The predicted value was used to establish a crossvalidated ROC curve. At the same time, 10 models were established, and 10 normalized mean square errors (NMSE) were obtained for the verification set and the average NMSE of the model was obtained to compare the reliability of the model. The smaller the NMSE, the more reliable the model is. Delong method was used to compare the significant difference between ROC curves, in which $\mathrm{P}<0.05$ indicated the difference was statistically significant. The Hosmer-Lemeshow goodness-of-fit test was used to test the predictive ability (calibration) of the model[13]. The model was evaluated with different indicators, including sensitivity, specificity, area under curve (AUC), and Youden Index, where the signature = sensitivity - (1-specificity). SPSS 13.0 for statistical analysis, R 3.2.3 software pROC package to do the Receiver Operating Curve (ROC) and ROC curve comparison. Bilateral test $\mathrm{P}<0.05$ showed statistically significant.

\section{Results}

\section{Patients Characteristics:}

A total of 2242 women were enrolled in the study and the age ranges from 18 to 46 years, with a mean age of 31.37 years. 978 patients had endometriosis while the rest were 860 patients with mature teratoma, 145 patients with serous cystadenomas, 183 patients with mucinous cystadenomas, and 76 patients with other benign conditions. The characteristics included baseline demographic, clinical, surgical, and laboratory features of patients with and without endometriosis (Table 1). 
Table 1

Comparison of Characteristics Between Endometriosis with Benign Ovarian Cysts

\begin{tabular}{|c|c|c|c|c|}
\hline Variables & $\begin{array}{l}\text { Non-endometriosis }(n= \\
1264)\end{array}$ & $\begin{array}{l}\text { Endometriosis } \\
(n=978)\end{array}$ & Statistic & $\begin{array}{l}\mathrm{P}- \\
\text { value }\end{array}$ \\
\hline Age (years) & $30.94 \pm 6.816$ & $31.92 \pm 5.381$ & $t=-3.709$ & $\begin{array}{l}< \\
0.001\end{array}$ \\
\hline BMI(kg/m2) & $21.48 \pm 2.982$ & $21.01 \pm 2.902$ & $t=3.701$ & ¿ 0.001 \\
\hline Mature delivery(n) & $1(0-5)$ & $1(0-5)$ & $Z=-4.459$ & $\stackrel{<}{0.001}$ \\
\hline Premature delivery(n) & $0(0-2)$ & $0(0-1)$ & $Z=-1.306$ & 0.192 \\
\hline Abortion (n) & $1(0-12)$ & $1(0-10)$ & $Z=-0.222$ & 0.824 \\
\hline Menstrual cycle(days) & $30.77 \pm 5.553$ & $29.54 \pm 3.234$ & $t=6.156$ & $\dot{0.001}$ \\
\hline $\begin{array}{l}\text { Duration of menstrual flow } \\
\text { (days) }\end{array}$ & $5.39 \pm 1.395$ & $5.81 \pm 1.534$ & $t=-6.860$ & ¿ 0.001 \\
\hline Irregular menstruation & $128(10.1 \%)$ & $35(3.6 \%)$ & $\begin{array}{l}\chi 2= \\
35.056\end{array}$ & $\begin{array}{l}< \\
0.001\end{array}$ \\
\hline Dysmenorrhea & $254(20.1 \%)$ & $358(36.6 \%)$ & $\begin{array}{l}x 2= \\
75.735\end{array}$ & $\begin{array}{l}< \\
0.001\end{array}$ \\
\hline Hyperlipidemia & $87(6.9 \%)$ & $55(5.6 \%)$ & $x 2=1.474$ & 0.256 \\
\hline History of caesarean & $204(16.1 \%)$ & $181(18.5 \%)$ & $x 2=2.174$ & 0.143 \\
\hline History of laparotomy & $375(29.7 \%)$ & $253(25.9 \%)$ & $x 2=3.946$ & 0.052 \\
\hline History of laparoscopy & $35(2.8 \%)$ & $35(3.6 \%)$ & $x 2=1.195$ & 0.274 \\
\hline History of hysteroscopy & $4(0.3 \%)$ & $25(2.6 \%)$ & $\begin{array}{l}x 2= \\
21.665\end{array}$ & $\dot{0} 001$ \\
\hline $\mathrm{CEA}(\mathrm{U} / \mathrm{mL})$ & $1.28(0-95.32)$ & $1.12(0-4.28)$ & $Z=-7.096$ & ¿ \\
\hline CA-125(U/mL) & $15.54(3.10-469.10)$ & $45.35(4.80-660.40)$ & $Z=-31.622$ & $\begin{array}{l}<.001 \\
0.00\end{array}$ \\
\hline CA-19-9(U/mL) & $19.13(0-1147.23)$ & $31.84(0-1128.52)$ & $Z=-6.854$ & $\begin{array}{l}< \\
0.001\end{array}$ \\
\hline $\begin{array}{l}\text { Neutrophil } \\
\text { count }\left(\mathrm{X} 10^{3} / \mathrm{mm}^{3}\right)\end{array}$ & $3.96(1.16-19.96)$ & $3.86(1.25-14.40)$ & $Z=-0.246$ & 0.806 \\
\hline
\end{tabular}




\begin{tabular}{|c|c|c|c|c|}
\hline Variables & $\begin{array}{l}\text { Non-endometriosis }(n= \\
1264)\end{array}$ & $\begin{array}{l}\text { Endometriosis } \\
(\mathrm{n}=978)\end{array}$ & Statistic & $\begin{array}{l}\mathrm{P} \text { - } \\
\text { value }\end{array}$ \\
\hline $\begin{array}{l}\text { Lymphocyte } \\
\text { count }\left(\mathrm{X} 10^{3} / \mathrm{mm}^{3}\right)\end{array}$ & $1.83(0.31-4.45)$ & $1.76(0.25-4.69)$ & $Z=-3.253$ & 0.001 \\
\hline NLR & $2.17(0.56-31.26)$ & $2.22(0.65-21.98)$ & $Z=-1.762$ & 0.078 \\
\hline $\begin{array}{l}\text { monocyte count } \\
\left(\mathrm{X} 10^{3} / \mathrm{mm}^{3}\right)\end{array}$ & $0.42(0.09-1.46)$ & $0.42(0.11-1.50)$ & $Z=-1.758$ & 0.079 \\
\hline Platelet count $\left(\mathrm{X} 103 / \mathrm{mm}^{3}\right)$ & $211.00(72.00-516.00)$ & $\begin{array}{l}213.00(61.00- \\
418.00)\end{array}$ & $Z=-0.785$ & 0.443 \\
\hline MPV & $10.70(6.90-14.50)$ & $10.70(6.40-14.40)$ & $Z=-0.812$ & 0.417 \\
\hline Hemoglobin, g/dL & $120.00(62.00-156.00)$ & $\begin{array}{l}117.00(65.00- \\
149.00)\end{array}$ & $Z=-5.849$ & $<0.001$ \\
\hline MCV & $88.45(56.80-103.40)$ & $\begin{array}{l}88.30(60.20- \\
99.20)\end{array}$ & $Z=-1.146$ & 0.252 \\
\hline $\mathrm{MCH}$ & $29.80(18.00-35.50)$ & $\begin{array}{l}29.60(18.20- \\
34.40)\end{array}$ & $Z=-3.337$ & 0.001 \\
\hline $\mathrm{MCHC}$ & $335.00(280.00-368.00)$ & $\begin{array}{l}333.00(288.00- \\
363.00)\end{array}$ & $Z=-4.097$ & $<.001$ \\
\hline \multicolumn{5}{|c|}{$\begin{array}{l}\text { Abbreviations: BMI, body mass index; MPV, mean platelet volume; NLR, neutrophil-to-lymphocyte ratio; } \\
\text { MCH, mean corpuscular hemoglobin; MCHC, mean corpuscular hemoglobin concentration; } \mathrm{P}<0.05 \text { is } \\
\text { considered as statistically significant. }\end{array}$} \\
\hline
\end{tabular}

\section{Clinicopathological Features With Endometriosis:}

After analysis of endometriosis with clinicopathological features, we found that there was no statistical significance with premature delivery $(P=0.192)$, abortion $(P=0.824)$, hyperlipidemia $(P=0.256)$, history of caesarean $(P=0.143)$, history of laparotomy $(P=0.143)$, history of laparoscopy $(P=0.143)$, Neutrophil count $(P=0.806)$, NLR $(P=0.078)$, monocyte count $(P=0.079)$, Platelet count $(P=0.443), M P V(P=$ $0.417)$ and MCV $(P=0.252)$. Further analysis showed that age, $B M I$, mature delivery, menstrual cycles, duration of menstrual flow, irregular menstruation, dysmenorrhea, history of hysteroscopy, CEA, CA 125, CA-19-9, hemoglobin, MCHC $(P<0.001)$, lymphocyte count $(P=0.001)$ and $\mathrm{MCH}(P=0.001)$ were statistically associated with endometriosis (Table 1).

\section{Univariate And Multivariate Analysis:}

We selected 16 variables to establish the multivariate logistic regression analysis. As a result, 11 variables were retained in the final logistic regression model (Table 2), it revealed that Log(CA-125), 
dysmenorrhea, history of hysteroscopy, age and mature delivery remained as significant variables associated with endometriosis. The Hosmer-Lemeshow test results revealed an adequate goodness-offit for the regression model $(P>0.05)$. The association between characteristics and diagnosis of endometriosis was explored and shown in (Table 3 ), all the models (model $1 \sim$ model 5 ) were significantly associated with endometriosis. A ROC curve for the model with CA-125 alone was constructed (Fig. 1), the area under the curve was $0.888(P<0.001)$ for the model, with a sensitivity of $0.816 \%$ and specificity of $0.835 \%$, These results indicate a moderate predictive performance of the model,after adjustment for other multiple covariates, the result presented a little rise of accuracy in diagnosis of endometriosis. The modle5 of included other values (combined clinical characteristics and haematological indexes) in the CA-125 based probabilistic model showed an AUC of $0.916(P \otimes 001)$, a sensitivity of 0.849 and specificity of 0.864 (Fig. 2), The Hosmer- Lemeshow test $(p=0.060)$ in the combined model5 indicate a good fitness of the model characteristic (dysmenorrhea, Irregular menstruation,), laboratory characteristics (Platelet count, monocyte count, CA-19-9, CA-125, CEA).

Table 2

Multivariate logistic regression model of morbidity risk in endometriosis.

\begin{tabular}{|lllllll|}
\hline Variables & $\boldsymbol{\beta}$ & S.E. & Wals & OR & $95 \%$ Cl & $P$-Value \\
\hline Age & 0.126 & 0.013 & 87.396 & 1.134 & $1.105-1.165$ & $<0.001$ \\
\hline mature delivery & -0.647 & 0.110 & 34.303 & 0.524 & $0.422-0.650$ & $<0.001$ \\
\hline Irregular menstruation & 0.955 & 0.276 & 11.941 & 2.600 & $1.512-4.469$ & $<0.001$ \\
\hline Dysmenorrhea & 0.569 & 0.142 & 16.051 & 1.767 & $1.337-2.334$ & $<0.001$ \\
\hline Menstrual period & 0.259 & 0.047 & 30.897 & 1.296 & $1.183-1.420$ & $<0.001$ \\
\hline History of hysteroscopy & 2.017 & 0.696 & 8.395 & 7.518 & $1.921-29.430$ & $<0.001$ \\
\hline CEA & -0.878 & 0.104 & 71.874 & 0.415 & $0.339-0.509$ & $<0.001$ \\
\hline CA-19-9 & -0.003 & 0.001 & 12.340 & 0.997 & $0.996-0.999$ & $<0.001$ \\
\hline monocyte count & -1.386 & 0.383 & 13.116 & 0.250 & $0.118-0.530$ & $<0.001$ \\
\hline Platelet count & -0.003 & 0.001 & 5.351 & 0.997 & $0.995-1.000$ & $<0.001$ \\
\hline Log(CA-125) & 7.059 & 0.307 & 528.6 & 1162.7 & $637-2122.4$ & \\
\hline Constant & -13.619 & 0.803 & 287.9 & 0.000 & & \\
\hline
\end{tabular}


Table 3

Logistic regression models fitting results of the association between non-endometriosis and endometriosis

\begin{tabular}{|c|c|c|c|c|c|c|c|c|}
\hline Models & $\begin{array}{l}H-L \\
\text { test }\end{array}$ & $Z$ & $P$-value & AUC & Sensitivity & Specificity & $\begin{array}{l}\text { Youden } \\
\text { index }\end{array}$ & NMSE \\
\hline $\begin{array}{l}\text { Model } \\
1^{\text {a }}\end{array}$ & $\begin{array}{l}< \\
0.001\end{array}$ & 7.167 & $<0.001$ & 0.888 & 0.816 & 0.835 & 0.651 & 0.556 \\
\hline $\begin{array}{l}\text { Model } \\
2^{b}\end{array}$ & $\begin{array}{l}< \\
0.001\end{array}$ & 6.666 & $<0.001$ & 0.891 & 0.843 & 0.816 & 0.659 & 0.545 \\
\hline $\begin{array}{l}\text { Model } \\
3^{c}\end{array}$ & $\begin{array}{l}< \\
0.001\end{array}$ & 6.320 & $<0.001$ & 0.899 & 0.836 & 0.833 & 0.669 & 0.511 \\
\hline $\begin{array}{l}\text { Model } \\
4^{d}\end{array}$ & $\begin{array}{l}<.001 \\
0.001\end{array}$ & 4.191 & $<0.001$ & 0.911 & 0.885 & 0.813 & 0.698 & 0.477 \\
\hline $\begin{array}{l}\text { Model } \\
5^{\mathrm{e}}\end{array}$ & 0.060 & Reference & Reference & 0.919 & 0.849 & 0.864 & 0.713 & 0.441 \\
\hline $\begin{array}{l}\text { a Only Ch } \\
\text { history, } \\
\text { variables }\end{array}$ & $\begin{array}{l}25 \text { in th } \\
\text { ariables } \\
7 \text { mode }\end{array}$ & $\begin{array}{l}\text { model, }{ }^{b} \text { va } \\
\text { model } 3 \text { p } \\
\text { except CA }\end{array}$ & $\begin{array}{l}\text { bles in mo } \\
\text { s mature d } \\
5 \text { was repl }\end{array}$ & $\begin{array}{l}\text { I plus } \\
\text { ery, his } \\
\text { ed by lc }\end{array}$ & $\begin{array}{l}\text { ge, }{ }^{c} \text { variabl } \\
\text { ry of hyster } \\
\text { (CA125) }\end{array}$ & $\begin{array}{l}\text { in model } 2 \\
\text { sopy, clinic }\end{array}$ & $\begin{array}{l}\text { lus reproc } \\
\text { character }\end{array}$ & $\begin{array}{l}\text { ctive } \\
\text { tic, e }\end{array}$ \\
\hline
\end{tabular}

\section{Discussion}

Endometriosis can only be diagnosed by invasive procedures such as laparoscopic or laparotomy exploration. We constructed a non-invasive predictive model based on medical history and hematological indexes (blood routine, serum tumor markers examination) that can diagnose endometriosis in ovarian cyst patients. We found association between the CA-125, CA-19-9, age, partus matures, menstrual episodes, history of hysteroscopy, dysmenorrhea and blood routine test with endometriosis, but no single characteristic predicted endometriosis with a high accuracy. Our study supported the retrograde menstruation theory because the history of hysteroscopy is shown to be associated with an increase in risk of developing endometriosis.

Our study confirmed the belief that an increased frequency of and duration of menstruations is associated with endometriosis $[14,15]$. Dysmenorrhea was the main symptom of endometriosis infertile women (46.92\%) with endometriosis and the mechanism of dysmenorrhea in endometriosis lie in increased production of prostaglandins (PGs)[16]. Moreover, BMI showed a negative correlation with the presence of endometriosis, as was reported previously[17]. Obesity is often associated with long menstrual cycles, a factor that reduce the risk of endometriosis. It is considered that the reduction of the frequency of menstrual episodes counterbalances the relative hyperestrogenism of women[18].

Endometriosis is rare before the menarche and tends to decrease after the menopause. Studies conducted in women under age of 45 years suggested that the frequency of endometriosis increases with 
age until menopause[19]. While Fuldeore, M. J, et al [2] reported that the average age of women with endometriosis in their study was 37.8 years compared to 33.8 years women without endometriosis $(\mathrm{p}<$ 0.0001 ), it is possible that incidence of endometriosis increases as women age increases which can be because of the hormonal changes that occur during peri-menopause[20].

Screening for the diagnosis of patients with clinical suspicion of endometriosis is based on serum CA125 which have been confirmed in many studies. Shen, $A$ et al [21] reported that endometriosis is significantly associated with elevated serum CA- 125 concentrations, confirmed CA- 125 as an auxiliary biological marker in endometriosis diagnosis. Some studies[22, 23] did not agree with this finding and showed that the diagnosis of endometriosis on CA-125 alone is not accurate, mainly in relation to their sensitivity, Hirsch, M, et al[23] reported that CA-125 with a cut-off of $\geq 30 \mathrm{u} / \mathrm{ml}$ has a sensitivity of 0.57 , which did not meet the criteria for a triage test, and international guidelines do not recommend CA-125 testing in women with suspected endometriosis[24]. However, in the study we find model 1 which consisted of CA-125 alone predicted endometriosis with high sensitivity (81.6\%) and predicted the absence of endometriosis with a specificity of $83.5 \%$. Nevertheless the timing of blood collection for CA125 is uncontrolled because it's a retrospective design, the relationship with the menstrual cycle is known to affect this test[25].

The study shows an inverse association between the number of mature delivery and endometriosis, but no association between the number of abortions and endometriosis has been found. This has also been observed in many studies of endometriosis[14, 26]. Parazzini, F, et al [26]reported that the risk of endometriosis decreased with increasing number of births, compared with nulliparous women, the OR of endometriosis at stage 1 was $0.1(95 \% \mathrm{Cl} 0.1,0.2)$ in women reporting two or more births was respectively $0.1(95 \% \mathrm{Cl} 0.1,0.3), 0.2(95 \% \mathrm{Cl} 0.1,0.4)$.

It has been reported that [27] reproductive history may influence hormonal milieu, Estradiol levels is higher among nulliparous women than among parous women, whereas androgen levels have an opposite effect, and reproductive history may influence the volume of endometrial cells released into the peritoneal cavity. The other studies revealed that CA-19-9 can be used to discriminate between patients with or without endometriosis, and it is correlation to severity of the disease, their results showed that CA-19-9 was significantly associated with advanced stage (stage III and IV) endometriosis[10]. Our results is in concordance with a former study that the mean levels of CA-19-9 are significantly elevated compared with the control group.

Endometriosis is associated with increased inflammatory activity which is an important stimulant for platelets[28], suggest platelet indices is an important and effortless hematological parameter that can be useful in evaluation of endometriosis[29, 30]. Evsen, M. S et al reported that platelets count in patients with peritoneal endometriosis were found to be higher from the control group $(p=0.038)$ [30], particularly more apparent in advanced stage peritoneal endometriosis. Monocytes also was also implicated as prognostic factor of inflammatory response but there is no evidence supporting that monocyte count is associated with endometriosis, our study shows that it is a protective factor for endometriosis, further 
study should be done to confirm this finding. This model provides guidance about confirmation of endometriosis. CA-125 can be useful in directing the diagnosis of the disease, and clinical history, tumor marker and routine blood tests increase the diagnosis of endometriosis more accurately. For instance, a peri-menopause woman with multiple reproductive history and irregular menstruation, has a higher chance of containing endometriosis, and if CA-125 is quite high, ovarian cysts would be appropriate to confirm the presence of the disease.

\section{Conclusion}

In this study, we found that CA-125, clinical history, tumor marker and routine blood term testing are predictors of endometriosis. Our model can contribute in diagnosis as a predictor for endometriosis in patients with ovarian cysts.

\section{List Of Abbreviations}

\begin{tabular}{|ll|}
\hline Abbreviation & Full name \\
\hline CEA & carcinoembryonic antigen \\
\hline BMI & body mass index \\
\hline NMSE & normalized mean square errors \\
\hline AUC & area under curve \\
\hline ROC & receiver operating curve \\
\hline
\end{tabular}

\section{Declarations}

\section{Ethics approval and consent to participate}

Ethics approval was obtained from Second Affiliated Hospital of Wenzhou Medical University Ethics Committee, and informed consent was obtained from individual participants prior to surgery.

\section{Consent for publication}

Not applicable

\section{Availability of data and material}

The datasets used or analysed during the current study are available from the corresponding author on reasonable request.

\section{Competing interests}


We declare that we do not have any commercial or associative interest that represents a conflict of interest in connection with the work submitted.

\section{Funding}

No external funding was used in this conduct of this study.

\section{Authors' contributions}

Junmiao Xiang contributed to the conception of the study.

Ping Duan contributed significantly to analysis and manuscript preparation.

Wei Shen performed the data analyses.

Zongwen Liang and Qiong Zhang helped perform the analysis with constructive discussions.

\section{Acknowledgements}

I would like to express my gratitude to all those who helped me during the writing of this paper. My deepest gratitude goes first and foremost to Professor Ping Duan, my supervisor, for her constant encouragement and guidance. And the author gratefully acknowledge the support of the Second Affiliated Hospital of Wenzhou Medical.

\section{References}

1. Giudice LC, Kao LC. Endometriosis. The Lancet. 2004;364(9447):1789-99.

2. Fuldeore MJ, Soliman AM. Prevalence and Symptomatic Burden of Diagnosed Endometriosis in the United States: National Estimates from a Cross-Sectional Survey of 59,411 Women. Gynecol Obstet Invest. 2016.

3. Halme J, Hammond MG, Hulka JF, Raj SG, Talbert LM. Retrograde menstruation in healthy women and in patients with endometriosis. Obstet Gynecol. 1984;64(2):151-4.

4. Ballard KD, Seaman HE, de Vries CS, Wright JT. Can symptomatology help in the diagnosis of endometriosis? Findings from a national case-control study - Part 1. BJOG. 2008;115(11):1382-91.

5. Lattarulo S, Pezzolla A, Fabiano G, Palasciano N. Intestinal endometriosis: role of laparoscopy in diagnosis and treatment. Int Surg. 2009;94(4):310-4.

6. Eskenazi B, Warner M, Bonsignore L, Olive D, Samuels S, Vercellini P. Validation study of nonsurgical diagnosis of endometriosis. Fertil Steril. 2001;76(5):929-35.

7. Vigano P, Parazzini F, Somigliana E, Vercellini P. Endometriosis: epidemiology and aetiological factors. Best Practice Research in Clinical Obstetrics Gynaecology. 2004;18(2):177-200.

8. Gupta D, Hull ML, Fraser I, Miller L, Bossuyt PMM, Johnson N, et al. Endometrial biomarkers for the non-invasive diagnosis of endometriosis. Cochrane Database Syst Rev. 2016;4:Cd012165. 
9. Nisenblat V, Bossuyt PMM, Shaikh R, Farquhar C, Jordan V, Scheffers CS, et al. Blood biomarkers for the non-invasive diagnosis of endometriosis. Cochrane Database Syst Rev, 2016(5): p. Cd012179.

10. Kurdoglu Z, Gursoy R, Kurdoglu M, Erdem M, Erdem O, Erdem A. Comparison of the clinical value of CA-19-9 versus CA 125 for the diagnosis of endometriosis. Fertil Steril. 2009;92(5):1761-3.

11. Zhang Z. Univariate description and bivariate statistical inference: the first step delving into data. Ann Transl Med. 2016;4(5):91.

12. Zhang Z. Variable selection with stepwise and best subset approaches. Ann Transl Med. 2016;4(7):136.

13. Zhang Z. Residuals and regression diagnostics: focusing on logistic regression. Ann Transl Med. 2016;4(10):195.

14. Burghaus S, Klingsiek P, Fasching PA, Engel A, Haberle L, Strissel PL, et al. Risk Factors for Endometriosis in a German Case-Control Study. Geburtshilfe Frauenheilkd. 2011;71(12):1073-9.

15. Cramer DW, Wilson E, Stillman RJ, Berger MJ, Belisle S, Schiff I, et al. The relation of endometriosis to menstrual characteristics, smoking, and exercise. JAMA. 1986;255(14):1904-8.

16. Koike $\mathrm{H}$, Ikenoue T, Mori N. [Studies on prostaglandin production relating to the mechanism of dysmenorrhea in endometriosis]. Nihon Naibunpi Gakkai Zasshi. 1994;70(1):43-56.

17. Lafay Pillet MC, Schneider A, Borghese B, Santulli P, Souza C, Streuli I, et al. Deep infiltrating endometriosis is associated with markedly lower body mass index: a 476 case-control study. Hum Reprod. 2012;27(1):265-72.

18. Calhaz-Jorge C, Mol BW, Nunes J, Costa AP. Clinical predictive factors for endometriosis in a Portuguese infertile population. Hum Reprod. 2004;19(9):2126-31.

19. Eisenberg VH, Weil C, Chodick G, Shalev V. Epidemiology of endometriosis: a large population-based database study from a healthcare provider with 2 million members. BJOG. 2017.

20. SA M, DW. C. The epidemiology of endometriosis. Obstet Gynecol Clin North Am. 2003;30(1):1-19.

21. Shen A, Xu S, Ma Y, Guo H, Li C, Yang C, et al. Diagnostic value of serum CA-125, CA19-9 and CA15-3 in endometriosis: A meta-analysis. J Int Med Res. 2015;43(5):599-609.

22. Rosa ESAC, Rosa ESJC, Ferriani RA. Serum CA-125 in the diagnosis of endometriosis. Int J Gynaecol Obstet. 2007;96(3):206-7.

23. Hirsch M, Duffy JMN, Deguara CS, Davis CJ, Khan KS. Diagnostic accuracy of Cancer Antigen 125 (CA-125) for endometriosis in symptomatic women: A multi-center study. Eur J Obstet Gynecol Reprod Biol. 2017;210:102-7.

24. Dunselman GA, Vermeulen N, Becker C, Calhaz-Jorge C, D'Hooghe T, De Bie B, et al. ESHRE guideline: management of women with endometriosis. Hum Reprod. 2014;29(3):400-12.

25. Spaczynski RZ, Duleba AJ. Diagnosis of endometriosis. Semin Reprod Med. 2003;21(2):193-208.

26. Parazzini F, Ferraroni M, Fedele L, Bocciolone L, Rubessa S, Riccardi A. Pelvic endometriosis: reproductive and menstrual risk factors at different stages in Lombardy, northern Italy. J Epidemiol Community Health. 1995;49(1):61-4. 
27. Missmer SA, Hankinson SE, Spiegelman D, Barbieri RL, Malspeis S, Willett WC, et al. Reproductive history and endometriosis among premenopausal women. Obstet Gynecol. 2004;104(5 Pt 1):96574.

28. Bullon P, Navarro JM. Inflammasome as a key pathogenic mechanism in endometriosis. Curr Drug Targets. 2017;18(9):997-1002.

29. Avcioglu SN, Altinkaya SO, Kucuk M, Demircan-Sezer S, Yuksel H. Can platelet indices be new biomarkers for severe endometriosis? ISRN Obstet Gynecol. 2014;2014:713542.

30. Evsen MS, Soydinc HE, Sak ME, Ozler A, Turgut A, Celik Y, et al. Increased platelet count in severe peritoneal endometriosis. Clin Exp Obstet Gynecol. 2014;41(4):423-5.

\section{Figures}

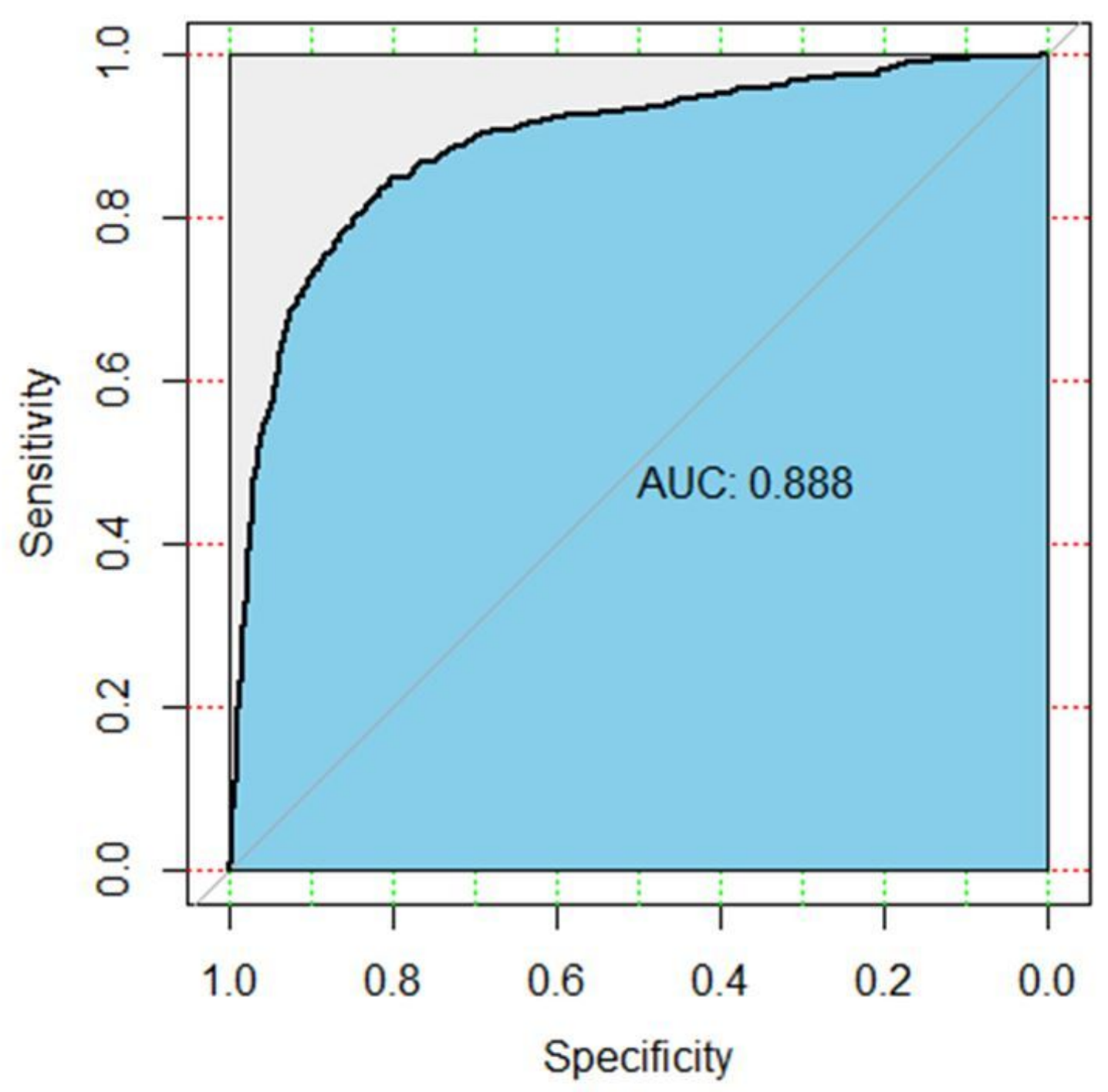

Figure 1 
ROC curve of the model1.

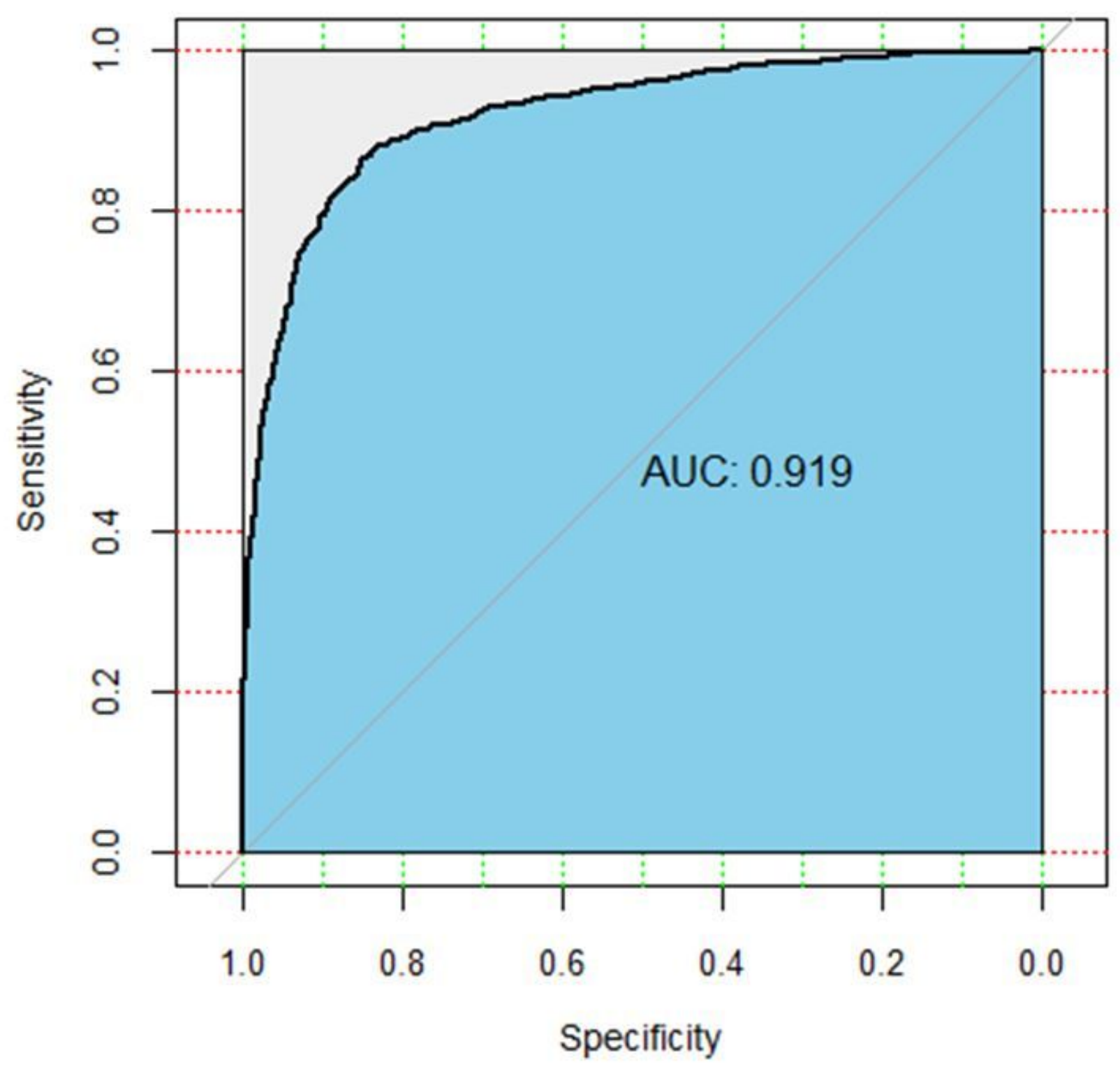

Figure 2

ROC curve of the new model5 